\title{
Inactivación de Escherichia coli 0157:H7 por el Efecto Combinado de Altas Presiones Hidrostáticas $Y$ Nisina En Buffer PBS
}

\author{
Mariana Cap (I), Yanina Barrio (I,III), Ana Maria Sancho (I), \\ Gerónimo Ortigoza (I), Claudio Sanow (I), Sergio Vaudagna (I,II,III), \\ Marcelo Masana (I) \\ (I) ITA, CIA, INTA - Instituto de Tecnología de Alimentos (Morón, Buenos Aires, Argentina), (II) \\ CONICET - Consejo Nacional de Investigaciones Científicas y Técnicas (Argentina), (III) UADE \\ - Universidad Argentina de la Empresa (Argentina)
}

\section{Resumo}

Altas presiones hidrostáticas (APH) es una tecnología no térmica de procesamiento de alimentos, capaz de reducir la contaminación por microorganismos patógenos y alterativos, y asegurar la inocuidad. APH actúa principalmente sobre la membrana citoplasmática generando un daño letal o subletal dependiendo de la intensidad del proceso, de la resistencia intrínseca del microorganismo y de las condiciones del medio. La nisina es una bacteriocina producida en forma natural por la bacteria Lactococcus lactis spp, sin efecto inhibitorio significativo sobre el desarrollo de las bacterias Gram negativas, las que sin embargo pueden sensibilizarse a su acción por un aumento de la permeabilidad de las membranas celulares. El uso combinado de APH y nisina se enmarca en el concepto de combinación de vallas cuya finalidad es alcanzar un efecto aditivo. El objetivo de este trabajo fue evaluar la inactivación de cepas de Escherichia coli productores de toxina Shiga (STEC) por efecto de tratamientos con APH y el agregado de nisina en buffer fosfato-salino (PBS). El inóculo inicial en PBS consistió en un pool de 2 cepas autóctonas de Escherichia coli O157:H7 aisladas en frigoríficos de Argentina (colección del ITA, CIA, INTA Castelar) a una concentración de $10^{7} \mathrm{UFC} / \mathrm{ml}$. Se aplicó un diseño factorial de $2 \times 3$ con dos niveles de presión (O,1 y $350 \mathrm{MPa}, 5$ minutos) y 3 niveles de nisina $(0,100$ y $500 \mathrm{UI} / \mathrm{ml})$. Luego, las muestras fueron conservadas a $5^{\circ} \mathrm{C}$ y analizadas

\footnotetext{
Referência:

Mariana Cap, Yanina Barrio, Ana Maria Sancho, Gerónimo Ortigoza, Claudio Sanow, Sergio Vaudagna, Marcelo Masana. Inactivación de Escherichia Coli O157:H7 por El Efecto Combinado de Altas Presiones Hidrostáticas Y Nisina En Buffer PBS. In: Anais do $12^{\circ}$ Congresso Latinoamericano de Microbiologia e Higiene de Alimentos MICROAL 2014 [= Blucher Food Science Proceedings, num.1, vol.1]. São Paulo: Editora Blucher, 2014. DOI 10.5151/foodsci-microal-147
} 
en los días 1,7 y 14 pos-proceso, por recuento en diferentes medios. Se utilizó agar Tripticasa Soja con extracto de levadura (TSAEL) para el recuento de bacterias totales y agar selectivo Mac Conkey $\left(37^{\circ} \mathrm{C}, 24\right.$ horas) para el recuento de células viables no injuriadas, siendo la diferencia entre estos el número de células injuriadas. La presencia de nisina en muestras no presurizadas no presentó efecto inhibitorio. El efecto aislado de la presión produjo una reducción de 0,32 ciclos logarítmicos en TSAEL, mientras que el tratamiento combinado a $350 \mathrm{MPa}$ con $500 \mathrm{UI} / \mathrm{ml}$ de nisina fue el más efectivo, alcanzando 2,75 reducciones decimales. Esto sugiere un efecto aditivo de los factores. El nivel de injuria fue elevado en todas las muestras presurizadas con y sin nisina.

Palavras-Chave: APH, Buffer, Inactivación, Nisina, STEC O157:H7 Agência de Fomento: ITA-CIA-INTA 